\title{
O DESEJO LESBIANO NO CONTO DE ESCRITORAS BRASILEIRAS CONTEMPORÂNEAS
}

\author{
POR \\ CRISTINA FERREIRA-PINTO \\ The University of Texas at Austin
}

\section{O LESBIANISMO E A LITERATURA ERÓTICA FEMININA NO BRASIL}

No Brasil e, de modo geral, na América Latina, a existência de uma tradição lesbiana na literatura de autoria feminina não tem sido reconhecida pela crítica, fato já comentado por David William Foster (Sexual Textualities 10). A razão para a suposta ausência dessa tradição é o tabu que ainda cerca as relações homossexuais na América Latina, e a conseqüente censura e autocensura que impediriam a expressão do lesbianismo na literatura de mulheres. Por um lado, tratar de personagens lesbianos e do desejo homossexual entre mulheres poderia levar identificação dessas escritoras como lésbicas; por outro, uma literatura que desse expressão livre ao erotismo lesbiano seria rapidamente tachada de pornográfica, ambos rótulos indesejáveis dentro do contexto latino-americano.

A causa, entretanto, para o não reconhecimento, ou desconhecimento, da presença do sujeito e do desejo lesbianos em obras de escritoras latino-americanas jaz na mesma atitude ideológica que faz com que a mulher lésbica torne-se invisível aos olhos da sociedade. $\mathrm{O}$ sujeito lesbiano foge à definição aceita de "feminino", rompe radicalmente com os padrões de gênero estabelecidos, ao não se definir em função do desejo masculino e do sistema de reprodução biológica e de transmissão de valores econômicos e ideológicos. Por não ser possível categorizá-la dentro desses padrões, a lésbica termina reduzida ao "no-ser", ao que não se nomeia (e o que não se nomeia não existe): "the lesbian exists in a vacuum of unreadability and unnameability both socially and sexually" (Manzor-Coats xxii). Se assim é na sociedade, na literatura o reconhecimento de uma tradição lesbiana exige um certo tipo de leitor que possa resgatar o sujeito e o desejo lesbiano de sua invisibilidade, um leitor dotado de uma capacidade "queer" de leitura (Anzaldúa 257-58). Ou seja, é necessária uma abertura ideológica que permita ler nas entrelinhas, trazer à tona o palimpsesto e decifrar a função da ambigüidade no texto, e que resgate a homossexualidade feminina do espaço marginalizado da literatura pornográfica.

No Brasil, o desejo lesbiano aparece na literatura escrita por mulheres desde, pelo menos, as primeiras décadas do século XX. A tradição de uma literatura sobre temas e personagens lésbicos, no entanto, teria que ser estabelecida a partir dos olhos da crítica de hoje, quando já há espaço para um tipo de leitura como a que sugere Gloria Anzaldúa. Assim, é possível verificar a representação do desejo lesbiano em obras, por exemplo, da 
poeta Gilka Machado, de Raquel de Queiroz ou de Clarice Lispector no início de sua carreira. ${ }^{1}$ Numa das raras obras sobre o tema, O lesbianismo no Brasil (1987), Luís Mott dedica um longo capítulo a um levantamento das "lésbicas na literatura brasileira", abrangendo desde a literatura portuguesa do século XIV até a produção literária no Brasil no começo dos anos 80 . Usando como critério de seleção dos textos discutidos a presença de personagens lésbicos ou a abordagem do lesbianismo como tema, Mott inclui nesse capítulo principalmente obras de autores masculinos e até obras estrangeiras traduzidas e publicadas no Brasil, porém poucos títulos de autoria feminina. Segundo ele, a primeira obra de autora brasileira que enfoca o desejo lesbiano teria sido o romance Vertigem, de 1926, escrito por Laura Villares, escritora hoje pouco conhecida. A situação romanesca criada em Vertigem lembra sob muitos aspectos a relação de Léonie e Pombinha em $O$ cortiço (1889) de Aluísio Azevedo, sem ser, no entanto, tão "violento e carnal" como o romance naturalista, possivelmente porque, "por se tratar de uma escritora mulher, a autocensura tenha sido mais forte" (Mott 85).

A autocensura, que às vezes pode calar a expressão erótica feminina em todas suas formas, encontra-se obviamente enraizada nas práticas sociais vigentes que tanto procuram controlar a sexualidade feminina, como restringir o acesso da mulher a uma linguagem adequada à representação de sua sexualidade. É somente a partir de finais da década de 60 , quando as mulheres brasileiras ganham mais espaço no terreno sócio-político e um número maior de escritoras chega a alcançar reconhecimento de público e crítica, que o erotismo passa com mais freqüência a ser um aspecto integrante da literatura de mulheres. A partir dessa época, ou seja, nos últimos trinta anos, observa-se uma proliferação de discursos sobre a sexualidade (Manzor-Coats xxiv). Entretanto, se essa proliferação origina-se em parte no discurso social dominante com a função de regulamentar e catalogar o desejo e as atividades sexuais de homens e mulheres (Foucault 30-31, 35, 36), o erotismo na literatura escrita por mulheres, inclusive as brasileiras, funciona como "a source of power, change and creativity" (Lorde, in Humm 285). Surgem então livros como A casa da paixão (1972) de Nélida Piñon e, mais tarde, antologias coletivas de ficção erótica feminina, tais como Muito prazer (1980) e O prazer é todo meu (1984), organizadas por Márcia Denser, ela própria autora de um importante corpus de ficção erótica feminina. O erotismo cínico, anti-romântico, e mesmo anti-erótico, de Denser é um excelente exemplo dos meios usados por escritoras brasileiras para problematizar as relações de gênero e examinar as hierarquias sociais e conflitos de poder freqüentes nas relações heterossexuais centradas no desejo masculino.

Sob este aspecto, outro livro relevante publicado naquele período é $O$ discurso da mulher absurda (1985), de Joyce Cavalcante, um volume de contos eróticos cujas protagonistas femininas situam-se como sujeito do desejo, buscando de modo "agressivo" (segundo os padrões masculinistas de comportamento feminino) o prazer sexual. No conto

\footnotetext{
'Ver, por exemplo, o poema "Impressões do gesto" (Mulher nua 1928) de Machado, que dá expressão ao desejo lesbiano ao representar o prazer sensual da voz poética feminina despertado por outra mulher; Queiroz, no romance As três Marias (1939), faz referência às "amizades viciosas" entre as internas e as órfãs do colégio; e, segundo indicação de Earl E. Fitz, já no primeiro romance de Lispector, Perto do coração selvagem (1944), a protagonista contempla a possibilidade de ter una relação homossexual. Lispector volta a abordar o lesbianismo em contos como "A solução" (de $A$ legião estrangeira 1964), "O corpo" (de A via crucis do corpo, 1974) e em A hora da estrela (1977).
} 
"Luta livre", por exemplo, a protagonista é uma mulher solteira de classe média que sai à noite procurando parceiros sexuais, e para cada amante que tem ela assume um nome diferente: Míriam, Cleide, Leila, Cláudia. Seus vários nomes representam a natureza esquiva da personagem frente aos homens com quem se relaciona. Essa posição esquiva e de mulher sexualmente experiente surpreende e incomoda seus amantes, assim como deve ter incomodado alguns leitores. Neste caso, o que perturba é o rompimento dos padrões de gênero, tanto pela personagem, ao assumir a posição de sujeito, como pela autora, que escreve de modo tão explícito sobre o erotismo feminino.

Se a expressão da experiência erótica feminina chega a ser tão problemática, a representação da sexualidade lesbiana o é ainda mais, pois rompe com as relações dominantes de gênero, ao excluir a figura do homem e colocar a mulher em uma posição de sujeito atuante, em vez do papel tradicional de objeto do desejo masculino. Assim, o desejo lesbiano na obra de escritoras brasileiras, não só representa uma dimensão importante da sexualidade feminina, como também serve para expor e questionar o controle social sobre a sexualidade e o corpo femininos. O lesbianismo abre um espaço para a realização pessoal e sexual da mulher, no qual a identificação com outro ser seu igual torna possível a autointegração do sujeito feminino. Como tem sido analisado pela teoria crítica contemporânea, as origens dessa identificação física e psíquica entre mulheres remonta ao Semiótico, quando a criança encontra-se num estágio de perfeita simbiose com a mãe. Esse primeiro estágio de união influencia as relações posteriores do sujeito e determina na mulher uma tendência à bissexualidade e a uma sexualidade mais fluida. ${ }^{2}$ O romance lesbiano Sortilegiu (1981), de Myriam Campello, ilustra bem essa identificação, neste trecho, por exemplo, em que a protagonista, Isola, conhece Marina, que mais tarde vai tornar-se sua amante: "Isola sentia a tepidez daquele corpo refletido sobre o seu no espelho, tocando-a, como se a fusão das duas imagens produzisse calor" (47). A imagem de dois corpos superpostos no espelho prenuncia o encontro sexual das duas mulheres, quando o corpo de uma funciona como o reflexo do da outra, e têm lugar a integração física e a reciprocidade no dar e receber prazer: "Marina [...] navegava Isola também multiplicando-se, desdobrada e vária como um prisma sob a luz. Isola/Marina se desencadeavam prazer como o vento no capim ondulante" (65).

Em seu livro Archetypal Patterns in Women's Fiction (1981), Annis Pratt comenta que "Through the experience of Eros with other women, [...] women experience themselves for the first time not as others but as essences, reaching that place in their consciousness where they can tap the sources of their own libidinal energy" (112). Treze anos depois, em uma obra mais teoricamente elaborada, Teresa de Lauretis chega a uma conclusão semelhante, ao afirmar que o desejo lesbiano "affirms and enhances the female-sexed subject and represents her possibility of access to a sexuality autonomous from the male" (xvii). A idéia de uma sexualidade feminina autônoma coloca-se em contraposição a um discurso social que privilegia o desejo masculino sobre o feminino, definindo o corpo da mulher exclusivamente dentro dessa hierarquia. Desse modo, a sexualidade e o desejo lesbianos podem ser entendidos como uma rejeição do sistema dominante, como o "ato de resistência"

\footnotetext{
${ }^{2}$ A bibliografia sobre o assunto é extensa mas poder-se-iam ver a respeito, entre outras, as seguintes obras: "The Laugh of the Medusa" (1976) e outros ensaios de Hélène Cixous; "Stabat Mater" (1986), de Julia Kristeva; e The Practice of Love (1994), de Teresa de Lauretis.
} 
formulado por Adrienne Rich em seu ensaio já clássico, "Compulsory Heterosexuality and Lesbian Existence" (1980). De Lauretis considera "the figure of the lesbian in contemporary feminist discourse [as representing] the possibility of female subject and desire: she can seduce and be seduced, but without losing her status as subject [...]" (156). De Lauretis refere-se à posição teórica que o lesbianismo ocupa na crítica feminista e, eu adiria, ao lugar que ocupa também no discurso literário, "a place from where female homosexuality figures, for women, the possibility of subject and desire" (De Lauretis 156). Diz ela:

To the extent that all women have access to that place, female homosexuality [...] guarantees women the status of sexed and desiring subjects, wherever their desire may be directed. [...] the desire expressed in the figure, in the trope, of female homosexuality may be predicated unconditionally of the female subject; it becomes one of her properties or constitutive traits. [...] [and] it need not be confined in the patriarchal frame of a "heterosexual love story" (156-57).

A proposição de De Lauretis oferece um enfoque útil para entender o desejo e o sujeito lesbianos nos contos que vão ser aqui discutidos. Em "Intimidade" (1977) de Edla Van Steen, "A mulher de ouro" (1980) de Myriam Campello, "A escolha" (1985) de Lygia Fagundes Telles, "Tigresa" (1986) de Márcia Denser, e "Fátima e Jamila" $(1976,1994)$ de Sonia Coutinho, a representação do desejo e da sexualidade lésbica privilegia notadamente a mulher como sujeito, ao mesmo tempo em que implica em uma crítica ao sistema de gêneros. Com exceção de "A escolha", no qual o erotismo tem lugar num marco temporal anterior à narrativa, todos são contos eróticos contrapondo-se àquele tipo de pornografia masculina na qual a homossexualidade feminina funciona como locus de prazer para o voyeur. Nestes contos, o desejo lesbiano representa uma ruptura com o contexto sóciosexual demarcado pelo patriarcalismo, um rompimento com as relações de gênero definidas pela "estória de amor heterossexual". Esta expressão é aliás sintomática da ideologia que limita a mulher a determinadas funções sociais e narrativas (e.g. a virgem que espera o casamento e a mulher "fácil" ou a prostituta), o que explica porque a própria palavra "amor" pode ser às vezes rejeitada, já que tem toda uma carga ideológica com conotações de amor romântico, relações hierárquicas, poder e submissão.

\section{O DESEJO LESBIANO EM CINCO CONTOS BRASILEIROS CONTEMPORÂNEOS}

Pode-se considerar que os contos a serem analisados a seguir formam parte de uma tradição lesbiana na literatura escrita por mulheres no Brasil. Entretanto, há que se reconhecer que caracterizá-los como narrativas lesbianas pode ser problemático, não só pelas questões de censura e autocensura a que me referi acima, mas em especial pela própria complexidade da discussão crítica em torno do que se poderia chamar "literatura lésbica". Críticas como Bonnie Zimmerman, Barbara Smith, Lillian Faderman e Marilyn R. Farwell, apresentam definições às vezes contraditórias entre si. Enquanto que Zimmerman é categórica, ao afirmar que "the nature of lesbian fiction makes it impossible to separate the text from the imagination that engenders it" (15), sendo portanto o texto lesbiano aquele escrito por uma mulher homossexual, Smith vêa crítica textual das instituições heterossexuais 
como o elemento caracterizador da narrativa lesbiana (188). Por outro lado, tanto Faderman quanto Farwell comentam as dificuldades e complexidade da questão e apontam o leitor como o "locus of the lesbian in the lesbian text" (Farwell Heterosexual Plots 7). Deste modo, corrobora-se a necessidade de uma leitura que dê nome existência ao personagem ou ao desejo lesbiano, ainda que o próprio texto não pareça fazê-lo abertamente.

No contexto cultural brasileiro, que muitas vezes se nega a dar rótulos rígidos, nem todas as personagens destes cinco contos se identificariam como homossexuais. ${ }^{3}$ Por exemplo, em "Intimidade", de Van Steen e "Fátima e Jamila", de Coutinho, temos personagens casadas vivenciando um momento de desejo homossexual. Estes dois contos seriam um exemplo do fenômeno histórico da "amizade romântica" entre mulheres casadas (Haggerty e Zimmerman 3); ambos, entretanto, lançam mão da sugestão, da ambigüidade e, no caso de Coutinho, de uma imagética forte, para criar situações de inequívoca carga erótica, que permitem lê-los como expressão de um desejo lesbiano. Falando da literatura anglo-americana novecentista, Vinetta Colby faz um comentário pertinente ao afirmar que, muitas vezes, na ficção de autoria feminina, a paixão entre mulheres "is sublimated in relationships that modern readers would immediately designate as lesbian" (Pratt 96). Nos contos de Van Steen e Coutinho, o desejo lesbiano transparece através de um erotismo denso e fundamentalmente carnal, e é tal "carnalidade" (Stimpson 301), que leva a enquadrar estes dois textos numa tradição literária lesbiana no Brasil. ${ }^{4}$

Já os contos "A escolha", de Telles, e "A mulher de ouro", de Campello, problematizam as relações de gênero na sociedade brasileira ao mesmo tempo em que enfocam, cada um à sua maneira, a questão da invisibilidade e "unnameability" do sujeito lesbiano. Enquanto Telles emprega com maestria a ambigüidade característica de sua ficção, Campelo solta a "gargalhada da Medusa", para usar a expressão de Hélène Cixous, e lança mão do humor e do sarcasmo como estratégias narrativas para forçar a abertura de um espaço onde seja possível representar o desejo lesbiano. Há nos dois contos um excesso textual - seja a ambigüidade que não se explica facilmente, seja o sarcasmo desafiante da voz narrativa-

\footnotetext{
${ }^{3}$ Creio que se pode identificar no caráter brasileiro (lembremo-nos de Macunaíma, o herói!) uma certa aversão a termos estritos de (auto)definição, o que vale tanto para questões de preferência sexual como de definição racial e étnica. Apesar do conhecido machismo brasileiro, há um considerável segmento da população, principalmente nos grandes centros urbanos, que vivencia a homossexualidade e a bissexualidade sem, contudo, ver como necessária definição categórica de suas identidades.

${ }^{4}$ Diz Catherine Stimpson em "Zero Degree Deviance" (1981): "[A lesbian] is a woman who finds other women erotically attractive and gratifying. Of course, a lesbian is more than her body, $[\ldots]$ but lesbianism partakes of the body [...] That carnality distinguishes it from gestures of political sympathy with homosexuals and from affectionate friendships in which women enjoy each other, support each other" (301). Enquanto que uma definição categórica do sujeito não se adequa ao contexto cultural brasileiro, o que me parece válido na proposição de Stimpson é que ela exclui as simples demonstrações de amizade ou apoio político entre mulheres. De qualquer modo, as categorias são sempre insatisfatórias e pecam pela rigidez. Deve-se lembrar, neste sentido, as palavras de Herbert Daniel: "A homossexualidade não se fecha numa definição, nem mesmo pode ser reconhecida como objeto definivel. É simplesmente uma forma de viver a sexualidade" (52).
} 
que vem exatamente do caráter excessivo do desejo e do corpo lesbiano. ${ }^{5}$ Enquanto que esse excesso é "descaradamente" anunciado pela protagonista de Campello, no conto de Telles ele reside nas reticências, na ambigüidade, naquilo que não se enuncia mas cuja presença, no entanto, é indubitável. Estes dois contos, como aliás "Tigresa" de Márcia Denser, correspondem a outro modo de entender a narrativa lesbiana, qual seja, a partir de uma economia textual desestabilizadora, tanto das categorias narrativas como de gênero (Farwell, Heterosexual Plots 8-9). O texto lesbiano, diz Farwell, apresenta "a disruptive female body that reorders the traditional narrative structure" (165). Diana Marini, a protagonista de "Tigresa", incorpora essa presença feminina perturbadora e excessiva, a partir da qual o texto se constrói como um discurso desordenado e transgressivo, crítico das relações sóciosexuais da burguesia brasileira.

\section{"InTimidade" E "Fátima e Jamila": a mulher "heterossexual" E o desejo lesbiano}

Edla Van Steen, que em 1977 ganhou o prêmio Revista Status de literatura erótica, enfoca em sua ficção o questionamento da identidade sexual de suas personagens e a subversão das categorias de gênero. Suas protagonistas freqüentemente encontram-se num processo de busca da auto-realização pessoal e sexual e da definição de um sentido de identidade. Essa busca, normalmente impossibilitada de atingir uma conclusão satisfatória no contexto patriarcal da sociedade brasileira, leva as personagens a criarem espaços alternativos onde a realização pessoal e sexual do sujeito feminino torna-se viável. Em "Intimidade", o desejo lesbiano vivenciado pelas duas personagens, Ema e Bárbara, representa tal espaço alternativo.

"Intimidade" constitui um instantâneo do cotidiano das duas amigas que vai revelar, para além dos atos rotineiros em primeiro plano, uma realidade mais profunda e mais íntima a partir da qual a intimidade entre as duas mulheres ganha uma nova dimensão. Ema e Bárbara são duas amigas inseparáveis, fisicamente parecidas, cujos maridos trabalham juntos e que ficaram grávidas e tiveram filhos ao mesmo tempo. Tudo aqui reforça a idéia de identidade entre as duas mulheres, inclusive a semelhança física entre as duas. A narrativa mostra-nos as duas conversando, já tarde da noite, numa hora em que as crianças estão dormindo e os maridos ausentes, propiciando assim um dos "raros [...] instantes de intimidade" (68) entre as duas mulheres. A brecha que então se abre na rotina vai se colocar em oposição ao cotidiano estruturado sobre o sistema de heterossexualidade compulsória. No conto, a cultura masculinista está representada na figura do marido, cuja presença implica no silêncio e na imobilidade da mulher que se sente nulificada: "Se o marido estivesse em casa a obrigaria a assistir à televisão, porque ele mal chegava, ia ligando o aparelho, ainda que soubesse que ela detestava sentar que nem múmia diante do aparelho"

\footnotetext{
${ }^{5}$ É comum nas culturas ocidentais a noção do corpo feminino como excessivo, porque é de seu caráter exceder, expelir, lançar para fora (secreções, a menstruação, o parto, etc.), e é esse excesso que o discurso dominante procura controlar de várias formas (Foucault 104 e seguintes). O corpo lesbiano seria então duplamente excessivo porque "[it] exceeds [the gender] system by being what the system constructs as the ultimate threat: a female body, a woman's sexuality, independent of the male" (Farwell "Lesbian Narrative" 161).
} 
(66). Ao contrário deste cenário estruturado sobre o desejo do homem, a presença da amiga cria um clima de intimidade, identificação, união, no qual tanto Ema quanto Bárbara agem espontaneamente, sentem-se elas mesmas, desoprimidas: "Um sentimento de liberdade interior brotava naquele silêncio" (68).

A partir de uma situação banal, na qual o desejo sexual pareceria soterrado pela domesticidade, a narrativa vai fornecendo-nos índices isolados da corporalidade das duas mulheres, da dimensão física que Bárbara e Ema assumem no imaginário uma da outra. Olhando Bárbara, Ema enxerga "uma linha de luz dourada [que] valorizava o perfil privilegiado" (65); a outra, por sua vez, admira "os cabelos soltos, caídos no rosto, [que] escondiam os olhos cinzas, azuis ou verdes" de Ema (66). E mais tarde: "Cintura fina, pele sedosa, busto rosado e um dorso infantil. [...] Louras e esguias, seriam modelos fotográficos, o que entendessem, em se tratando de usar o corpo" (67). De maneira fragmentária, esses índices vão apoiando a narrativa sobre o corpo feminino e vão prenunciando, ao mesmo tempo, o desejo homossexual que se manifesta quando as duas mulheres, com o pretexto de consertarem o sutiã de Ema, despem-se e comparam qual das duas tem os seios maiores e trocam então carícias. Note-se também a enunciação e o deslocamento de objetos normalmente erotizados em um discurso masculino, tais como o sutiã, o quarto de dormir e os lençóis novos na cama de Ema. Apresentados displicentemente como parte do cotidiano doméstico, esses objetos parecem perder sua carga de erotismo quando, na verdade, apenas servem para construir uma nova dimensão erótica já que aparecem exclusivamente em função do corpo e do desejo feminino. Ao final do conto, após essa manifestação de desejo sensual, as personagens sentem uma mescla de emoções, uma "tristeza delicada, de quem está de luto" (68), que a lembrança do cotidiano evoca e, ao mesmo tempo, um "sentimento místico, meio alvoroçado, de alguém que, de repente, descobriu que sabe voar" (68), representando-se o lesbianismo como um espaço de libertação e satisfação pessoal e sexual para o sujeito feminino.

Também no conto de Sonia Coutinho, "Fátima e Jamila", o desejo homossexual entre mulheres manifesta-se como um espaço alternativo que isola e une as duas personagens do título, apartando-as do espaço maior do desejo e do poder masculino. Este aparece claramente descrito na primeira parte do conto:

Sentado à cabeceira da mesa comprida armada na varanda dos fundos, benevolente e soberano como um chefe patriarcal, o Marido presidira o encontro de Homens em Trajes Escuros e as mulheres de cabelos em penteados altos, roupas volumosas enfeitadas com rendas e jóias em demasia: dignos representantes da Nobreza Colonial Extinta, exibindo um antigo luxo trazido em caravelas de Portugal (132).

O uso das maiúsculas, recurso bastante usado por Coutinho, apresenta a ordem social dominante sob uma ótica crítica, ao mesmo tempo em que a caracteriza como uma mentalidade colonial anacrônica. Essa realidade vai servir de pano de fundo ao espaço íntimo que se vai estabelecendo entre as duas protagonistas; é como se o foco de uma câmera cinematográfica, depois de um "establishing shot" em que apresenta o contexto social da ação narrativa, fosse se fechando pouco a pouco até enfocar exclusivamente as duas mulheres. Entretanto, a ação propriamente dita é quase inexistente e, sob este aspecto, o 
conto de Coutinho é menos explícito quanto à manifestação do desejo homossexual das duas personagens que o de Van Steen. Não há, por exemplo, nenhuma referência a carícias ou qualquer outro contato físico. O texto, entretanto está carregado de um erotismo pujante que se constrói pelas e nas próprias palavras. O erótico reside, antes de mais nada, no próprio texto, nas palavras cheias de sumo, de odores, de vida própria, excessiva, que conotam languidez e sensualidade. Veja-se um exemplo:

A brisa vinda do mar, lá longe, espalha pela sala o aroma pesado das frutas empilhadas nas cestas [...]: umbus cuja acidez termina em doçura final dissolvendo-se na boca, bananas pontudas e recurvas como adagas, mangas rosadas cabendo na mão feito seio ovalado e cujo grosso caldo amarelo escorre pelo queixo, cajus quase púrpura, o travo das pitangas (131-32).

Coutinho constrói um cenário que apela para todos os sentidos, inclusive o sonoro, combinando palavras que ora evocam lugares exóticos, ora alongam-se sensualmente no "espreguiçamento" fonético da aliteração e das proparoxítonas (por exemplo, "a requintada pourriture do Tokay"; "sabores aveludados e sápidos"; "As sombras já se alongam entre os troncos dosflamboyants e das acácias”; etc., 133). Vale lembrar aqui o comentário de Sylvia Molloy, que afirma:

Women's eroticism appears to express itself in forms more diverse [...] than the primarily sexual. [...] What one often finds in women writers, in terms of erotic desire, is a slippage from sex to text: the text itself is an erotic encounter in which the poet [or the writer] makes love to her words. [...] Not limited to the physical body, and certainly not repressing it, desire in these cases extends to the body of writing (120).

Coutinho utiliza a linguagem para construir um cenário altamente sensual ao que concorre também imagens e metáforas, tais como a orquídea que Fátima colhe entre as frutas na mesa. A orquídea, símbolo da sexualidade feminina, aparece aqui detalhadamente descrita por Fátima, que conclui: "As flores são hermafroditas" (133). Tal afirmação sublinha a presença dos símbolos sexuais, masculinos e femininos, presentes no parágrafo citado anteriormente e de outros que vão aparecer mais adiante.

A narrativa continua a enfatizar a qualidade excessiva dos objetos que compõem o cenário - o calor, o ar pesado, os cheiros, a vegetação exuberante- e que reflete o caráter excessivo da sexualidade feminina: "o ardor maduro do corpo de Fátima era o do excesso de sumo que precede a decomposição" (135). A sensualidade do cenário entretece-se com as poucas descrições físicas de Fátima (Jamila aparece somente de costas e na penumbra), seus poucos gestos misteriosos, e com as histórias de amor e sedução que ela narra à companheira, para armar então a cena-chave de sedução: "Quem você vai enfeitiçar, desta vez?" pergunta Jamila. A resposta encontra-se, novamente, não a nível do actante mas a nível textual, condensando-se o desejo homossexual em uma série de imagens dispostas metonimicamente: "Como se repentino o cantor de flamenco rompesse, no grito pungente da saeta, o silêncio branco/negro de casas caiadas sob o sol vertical do meio-dia - com estranha inquietação, [...] um arrepio de presságio descendo-lhe pelos rins, quem sabe a 
Compreensão, Fátima se voltou e viu o rosto de Jamila" (135). Fátima e Jamila deparamse assim no ambíguo jogo da sedução, em que cada uma representa o papel de quem seduz e de quem é seduzida. O desejo lesbiano coloca ambas na posição de sujeito do desejo, posição esta, como nos lembra Coutinho nesta e em outras obras suas, freqüentemente vedada à mulher dentro da ordem sócio-sexual dominante.

\section{O discurso transgressivo de Márcia Denser}

Diana Marini, protagonista paradigmática e cínica narradora dos contos de Márcia Denser, constantemente infringe as regras de comportamento ao assumir ela o papel normalmente reservado ao homem. Diana é a caçadora que busca ativamente o prazer pelo prazer;" não é a mulher passiva às investidas do homem, nem tampouco a prostituta disponível para satisfazer os desejos masculinos. Diana busca a satisfação do seu próprio desejo sexual e para tanto "utiliza a própria arma do dominador", ou seja, a sedução erótica. Por essa razão, "o homem, acostumado a 'controlar', vê-se inefíciente diante dela" (Franconi 57). Ao assumir o papel ativo no jogo da sedução, Diana desestabiliza as relações de gênero sem, entretanto, chegar a rompê-las: "[...] in the regime of compulsory heterosexuality, women's power of seduction [...] is the flip side of their powerlessness as objects of seduction" (De Lauretis 155). Diana caça suas presas sexuais (masculinas) mas suas armadilhas são os ditos ardis "femininos", porque ela aparentemente se submete aos homens com quem vai para a cama, embora tenha uma grande consciência crítica de sua posição, enquanto mulher, frente ao desejo masculino. O comportamento sexual de Diana assume uma dimensão subversiva porque ela se furta ao controle social do corpo feminino e recusa seu lugar no sistema de procriação e transmissão de valores econômicos e ideológicos. Entretanto, são as reflexões cínicas de Diana narradora, assim como o próprio estilo narrativo de Denser, que desestabilizam o sistema dominante de gêneros porque expõem criticamente as hipocrisias da sociedade brasileira (em particular de seu vasto segmento burguês) e problematizam as relações amorosas e sexuais entre homens e mulheres. A narrativa de Denser torna óbvia a maneira como os atos mecânicos, o interesse próprio e o gosto pelo poder impossibilitam a expressão autêntica de Eros.

Denser usa o erotismo para examinar as relações de poder, não apenas entre homens e mulheres, como também entre indivíduos de diferentes classes sociais e grupos raciais. Cabe ressaltar, aliás, que apesar de inverter o sistema de gêneros e adotar comportamentos geralmente inaceitáveis para a mulher, Diana Marini incorpora muito da ideologia burguesa preconceituosa, principalmente no que diz respeito às classes sociais mas também em relação à homossexualidade. Estes dois aspectos ficam bem exemplificados no conto "Tigresa", em que a protagonista expressa seu desdém por indivíduos das classes baixas ("Olhei-o dum jeito de estremecer até os bagos do seu tataravô, se é que essa gente tem raça. Brotam das lixeiras" 123-24) e seu incômodo quando confrontada com o desejo de outra mulher por ela ("Aquele olhar untuoso e apaixonado de odalisca me incomodava" 132). "Tigresa" é um ótimo exemplo do tipo de narrativa transgressora característica de Denser,

${ }^{6}$ A intencionalidade do nome da personagem, que se anuncia no título do livro, Diana Caçadora (1986), já foi observada pelos críticos, entre eles Rodolfo Franconi (1987) e Susan Quinlan (1991). 
fragmentada, rápida, caótica, com diálogos suspensos e o encadeamento dos pensamentos da protagonista, empenhada em sua avaliação apressada e sempre crítica do outro. Em "Tigresa", que se revela também um pouco comédia de erros, Diana é convidada por uma fã - inesperada e ardorosa - para uma festa. Chamada de "tigresa" pela moça, Lila, Diana imediatamente assume a máscara da mulher irresistível e sedutora, o papel da "escritora-sersuperior" cuja representação o álcool e a vaidade facilitam. O convite dá início ao jogo de sedução que continuará na festa, no apartamento de classe média-alta dos pais de Lila. Diana vai à festa, convencida de sua máscara, para descobrir que já outra pessoa havia armado um jogo de sedução com papéis marcados. Lila é então quem representa o papel de "tigresa": ela vai (tentar) seduzir Diana, troca beijos com outra mulher para escândalo de alguns convidados, e seduz, no sentido de fascinar, a todos os outros presentes. Entretanto, o comportamento homossexual de Lila não é tanto a expressão do seu desejo por Diana e pela outra mulher, como é, na verdade, resultado da vontade de "épater les bourgeois" (Faderman 50). Aliás, Rich lembra que em contextos culturais tais como o brasileiro, nos quais a homossexualidade feminina permanece "invisível", o lesbianismo reduz-se às vezes a um fenômeno das classes altas, onde os comportamentos ditos "decadentes" são vistos com um misto de fascinação e condescendência (Rich 156 n.44). Trazer Diana à festa tem assim, antes de mais nada, a função de marcar a diferença de Lila perante a família e os amigos.

Ao final do conto há outra vez uma troca de papéis, e de seduzida Diana passa de novo a sedutora:

[...] Lila segurou-me pelos ombros e debaixo do meu sono e cansaço percebi outra vez o olhar gorduroso do desejo. Está bem, pensei, eu me rendo, doce Lila, mas costumo terminar o que começo. Vamos ver até onde você vai.

[...] Lila encostou-se melosamente na parede, com infinitos dengos de sedução. [...] Então, calmamente mandei:

-Tira a roupa. $[\ldots]$

- Tira tudo. Se você quer é pra valer, meu bem. Lila engoliu o riso (135-36).

Diana utiliza as armas de Lila com o mesmo resultado que a outra pretendia alcançar: se Lila queria viver uma experiência homossexual para "épater les bourgeois" e demarcar um espaço próprio, é ela que, como boa filha de família burguesa, sai chocada e mesmo humilhada da experiência. No entanto, a protagonista afinal assume, não a máscara de tigresa, mas a pele do tigre que, acossado, acaba ferindo: "[...] não sei porque, lembrei aquela frase do Ernest Hemingway em As neves do Kilimanjaro a respeito de um tigre que foi encontrado morto, enregelado entre os cumes cobertos pela neve e que ninguém, ninguém jamais soube explicar como e por que ele chegou até lá" (136). É Diana, portanto, que marca sua diferença, seu espaço à parte, sua solidão, dentro do espaço maior da sociedade burguesa brasileira. 
Lygia Fagundes Telles e Myriam Campello: "to name or not to name, that is the QUESTION"

Em 1985, quando "A escolha" sai publicado, o lesbianismo já não era tema novo para Lygia Fagundes Telles. Em seu primeiro romance, Ciranda de pedra (1954), Telles já abordava o tema de maneira aberta, embora refletindo os preconceitos sociais dominantes então. Na obra, a personagem Letícia, depois de um amor heterossexual frustrado, passa a seduzir moças mais jovens para logo se apaixonar pela protagonista, Virgínia. Há uma cena em que as duas se beijam e Letícia propõe a Virgínia que vá morar com ela. Apesar de avançada para a época, a obra apresenta a homossexualidade de Letícia como um "mal" que ela causa a si mesma e às outras moças. Sua identidade homossexual aflora como conseqüência de uma desilusão com um homem e a própria Letícia assume uma posição masculinista em relação a suas amantes. Quase vinte anos depois, em As meninas (1973), Telles procura apresentar uma visão mais natural do lesbianismo, embora a experiência homossexual seja agora quase um acidente na vida da personagem. Lião, uma das três protagonistas, tem sua primeira experiência sexual com outra moça e essa iniciação é caracterizada como uma etapa no processo de crescimento da jovem, um fenômeno passageiro num processo de desenvolvimento que levará a mulher à "normalidade" heterossexual. $^{7}$

Enquanto que nestas obras Telles aborda o tema sem subterfúgios, é em contos como "A escolha" que o lesbianismo ocupa verdadeiramente o centro da narrativa, determinando inclusive a própria construção do texto. ${ }^{\circledR}$ Neste conto a autora problematiza a representação textual e social do sujeito e do desejo lesbianos, realizando aqui o que Foster, em outro contexto, caracterizou como um procedimento de "[textualizing] [...] the problems of writing about a subject that cannot be satisfactorily accommodated within the dominant discourse" (Gay and Lesbian 141). A solução que Telles encontra para esse problema de representação reflete a posição "invisível" da mulher lésbica na sociedade brasileira, cuja existência, em geral, ou é reconhecida através de expedientes irônicos que não a nomeiam ou é acolhida com violência, reduzindo-a à condição de prostituta e promíscua (Míccolis 8990). Para expor a nível textual esses dois modelos sociais de representação do sujeito e do desejo lesbiano, Telles os reproduz literariamente utilizando a imagem de rosas vermelhas para substituir paradigmaticamente o amor de duas mulheres, Gina e Oriana. As duas, na verdade, encontram-se ausentes do texto, Gina já morta e Oriana roubada de sua voz, afirmando-se suas presenças somente pelas rosas vermelhas que Oriana, calada mas teimosamente, deixa no túmulo de Gina. O conto é narrado por outra mulher, a mãe de Gina, cujas rosas brancas contrastam e competem com as vermelhas, assim como ela disputa o amor da filha, mesmo após sua morte, com a amante desta. A narradora "não-confiável" e a não enunciação da homossexualidade de Gina e Oriana estruturam a ambigüidade tão a

\footnotetext{
${ }^{7}$ Observações semelhantes são feitas por Pratt (97) sobre romances anglo-americanos publicados antes de 1970, e por Foster sobre $O$ cortiço (Sexual Textualities 2).

"Outro conto de Telles em que o desejo lesbiano ocupa uma posição central na narrative é "Tigrela", de Seminário dos ratos (1977). Eva Paulino Bueno apresenta uma boa análise da representação do desejo lesbiano neste conto em Latin American Writers on Gay and Lesbian Themes.
} 
gosto da autora. Narrado pela voz hostil e ciumenta da mãe, o relacionamento de Gina e Oriana vai situar-se no espaço oculto do quarto de portas fechadas e vozes abafadas. A perspectiva materna oferece uma visão ambígua da filha, "dissimulada" e "inocente" ao mesmo tempo (131), e vil de Oriana ("você é suja", 129), enquanto que o amor entre as duas, na imagem das rosas vermelhas, representa-se pelo excesso que socialmente caracteriza a sexualidade lesbiana. As rosas que a amante deposita para Gina são "vermelhonas, completamente desabrochadas [...] deslavadas ao sol, quase obscenas de tão abertas" (129). Contrastando com o excesso do "vermelho-negro" (129), o branco das rosas da mãe representa o discreto, o comedido, o socialmente aceito.

Colocada entre as duas, Gina é violentamente forçada a uma definição, num confronto que reproduz a violência com que a sociedade pode tratar a mulher lésbica: "[...] de repente comecei a gritar, batendo com os punhos nos joelhos" (131); "Faça o que quiser, vá-se embora com Oriana ou fique comigo, a decisão é sua, tem todo o direito de escolher" (133). A mãe empresta voz à ideologia dominante ao tentar controlar a sexualidade da fillha. Gina, entretanto, não escolhe nenhuma das duas opções que a sociedade, na figura da mãe, lhe impõe, e nem assume a marginalidade social da mulher lésbica, nem renuncia a seu amor por outra mulher: "Me lembrei de tanta coisa, tanta mas em nenhum instante me ocorreu que além das opções que the ofereci havia uma terceira. Que ela escolheu em surdina, fechada lá no seu mundo secreto" (133). O suicídio aparece assim como única resolução possível para o conflito em que a sociedade a lança. É, contudo, uma resolução novamente ambígua, expressão tanto da agência e autoridade da mulher lesbiana como de sua mudez, ato de silêncio que a retorna à invisibilidade a que a sociedade a confinou.

Myriam Campello, por sua vez, em "A mulher de outro", responde de modo bastante distinto à questão da (in) visibilidade do sujeito e do desejo lesbianos na sociedade brasileira e de que modo nomeá-los quando se tem como recurso um sistema sócio-lingüístico inadequado para tal. Ao contrário de Telles, que lança mão do próprio código social discriminatório ao tratar o tema do lesbianismo sem chegar a nomeá-lo, Campello força a abertura de um espaço para o sujeito lesbiano, enunciando desafiadoramente o desejo homossexual feminino. Ao fazê-lo, atreve-se a anunciar uma nova ordem, na qual a homossexualidade terá lugar reconhecido:

Aqui uma nota: Proust esperou até que a mãe morresse para poder dizer as coisas. Mas a minha está viva e terá que agüentar. Paciência, mamãe. Sei que tem vizinhos, parentes e amigos, mas a verdade queima, louca para sair. Além disso é bom ir se acostumando, gente fresca o lobo vai comer e lamber os beiços nesta década, para mim está claro como água (59).

De novo a figura materna encarna a ideologia dominante contra a qual a mulher homossexual tem que rebelar-se para afirmar sua verdade — sua sexualidade - recusando o pacto de silêncio estabelecido. Enunciando ostensivamente seu desejo sexual por outra mulher, a protagonista-narradora de Campello antecipa-se com muito sarcasmo a qualquer reação negativa que a sociedade (a mãe, os vizinhos, os parentes, quem sabe o leitor [...] pudesse expressar: "Oh, Senhor, o que fazer desse desejo? E, oh, Senhor, uma mulher!" (61). A enunciação inequívoca da sexualidade lesbiana, o humor e o sarcasmo são as 
estratégias narrativas utilizadas pela autora para dar ao sujeito homossexual feminino o espaço que lhe é devido.

Em a "A mulher de ouro", a protagonista-narradora conta como, após ter saído "do último casamento" (60), conhece em uma discoteca a mulher do título. O desejo lesbiano, no entanto, não é caracterizado como consolo para um amor heterossexual frustrado. $\mathrm{Na}$ verdade, Campello cria uma protagonista consciente de sua sexualidade, uma mulher que já viveu experiências tanto homossexuais como heterossexuais, ilustrando assim a idéia, encontrada em Foucault, Rich e mesmo em Freud (De Lauretis xiii, 41), de um "continuum sexual" no qual a homossexualidade e a heterossexualidade aparecem como expressões possíveis da sexualidade humana. Entretanto, o conto privilegia claramente o desejo lesbiano, enquanto critica as relações dominantes de gênero e o casamento firmado sobre "séculos de herança medieval, amor eterno, babaquices lançadas sobre [a mulher] [...]" desde que nasce (60). Desiludida afinal com as falsas promessas do amor romântico (heterossexual), a protagonista decide buscar "uma fórmula de contato humano" que não a aprisionasse (60), não a submetesse, uma relação não-hierárquica, entre iguais, e o desejo lesbiano acena com essa possibilidade. Com a "mulher de ouro" ela vive uma relação idílica de plena satisfação sexual, livre de vínculos sociais: "Não the perguntava nada. Mal sabia seu nome, evitando por minha vez lhe dar informações que penderiam incômodas" (63). O idílio, entretanto, chega ao fim quando a amante pronuncia a palavra proibida: "num momento de selvagem doçura a mulher de ouro [...] me olhando nos olhos disse que me amava. [...] Foi nossa última noite. Não quis mais vê-la" (63). Para a prot.lgonista, a declaração de amor da outra mulher evoca conotações de posse, submissão e hierarquia, comuns no amor heterossexual, e ela opta pelo rompimento, embora o final do texto sugira que tal opção é feita à custa do seu amor pela outra mulher.

"A mulher de ouro" acaba sendo uma história de amor lesbiano, romântico como uma história de amor heterossexual poderia ser. O que cabe ressaltar neste conto, no entanto, é a representação do amor homossexual entre mulheres como possível e natural, e do sujeito lesbiano como qualquer mulher, de qualquer grupo social ("Ela era diferente de mim. Simples, tímida, trabalhava em qualquer repartição do governo" 59). Ao lado do sarcasmo com que desafiadoramente Campello tira o sujeito lesbiano da sua invisibilidade e silêncio, observa-se também a preocupação de criar uma linguagem adequada para reproduzir da maneira a mais autêntica possível a vivência da mulher homossexual, em particular suas experiências sexuais e eróticas:

[...] uma febre oceânica me devorou, uma tempestade me comeu, toda a mitologia hindu visitava meus desvãos solitários enquanto Brahma, Vishnu e Siva corriam pelos nervos de raiz à mostra, o que era, Senhor, esse olho de tufão me empurrando pra fronteiras tão longínquas que eu nem sabia existirem. [...] e não eram só os orgasmos tremulando por meu corpo como carrilhões de catedral que me conduziam a essa perplexidade de prazer, era o espaço perfeito deixado por seu rastro na minha alma, uma anulação tão grande na plenitude que me vi à beira do êxtase religioso (61-62).

Campello alterna passagens eróticas como esta a trechos de muito humor em que se antecipa a uma possível reação negativa por parte do leitor frente ao erotismo lesbiano: 
"imagino que deva haver alguém na distinta platéia que se questione aflito, mas o que podem fazer duas mulheres juntas? Respostas para o Ministério da Educação" (62). A combinação desses dois registros lingüísticos, o erótico e o humorístico, sublinha o que parecem ser as intenções da escritora neste conto e, aliás, em outras obras suas: a abertura de um espaço narrativo onde seja possível a afirmação da identidade e sexualidade lesbianas e a criação de um discurso erótico feminino independente do desejo masculino e, concomitantemente, a conscientização do público leitor, preparando-o para a nova ordem social que ela anuncia.

Examinaram-se aqui cinco contos de escritoras brasileiras contemporâneas em que o desejo homossexual feminino ocupa uma posição central na narrativa, chegando a determinar a construção formal do relato. Apesar de o modo de representação do desejo lesbiano diferir nestes contos, em todos ele se apresenta como um locus que permite à mulher o exercício de sua subjetividade, abandonando ela a posição de objeto passivo ao qual tem sido limitada dentro do sistema de gêneros dominante. Desse modo, o lesbianismo não só abre um canal para a expressão autêntica do erotismo feminino como serve também para realizar uma crítica às relações heterossexuais hierárquicas.

As estratégias narrativas utilizadas por Edla Van Steen, Sonia Coutinho, Márcia Denser, Lygia Fagundes Telles e Myriam Campello vão desde a sugestão e a ambigüidade até o humor e a enunciação clara do sujeito e do desejo lesbianos. Nem sempre explícitos, estes contos exigem às vezes uma leitura "queer" que afirme aquilo que aí se acha presente mas não se nomeia: o desejo homossexual feminino. O conto de Telles é, talvez, o que melhor textualiza esse problema, ao trabalhar literariamente com um código cultural que torna o sujeito lesbiano socialmente invisível. De maneira semelhante, as narrativas de Van Steen e Coutinho armam-se sobre esse paradoxo, dando representação ao erotismo lesbiano sem, contudo, dar-lhe nome. Coutinho, aliás, escreve em "Fátima e Jamila" passagens de grande sensualidade e erotismo, numa expressão do erótico que transcende o puramente sexual para permear o textual. Também Campello trata de criar uma linguagem adequada à representação das experiências de vida - sexuais e não sexuais-da mulher lésbica. $\mathrm{O}$ conto de Denser, por sua vez, caracteriza-se como um discurso transgressivo que rompe e subverte o sistema dominante de gêneros; através da visão pessoal de sua protagonista, Diana Marini, a autora denuncia as práticas discursivas discriminatórias da homossexualidade feminina ao mesmo tempo em que expõe a apropriação do lesbianismo pelas classes burguesas brasileiras, que fazem daquele uma marca de diferença, quase se poderia dizer, um "símbolo de status".

Apesar das diferenças aqui verificadas, que respondem às diversas definições teóricas do lesbianismo na literatura, estes cinco contos exemplificam a construção de um espaço literário que afirma um lugar para a subjetividade lesbiana, um espaço onde tanto o personagem lésbico quanto outros personagens femininos podem vivenciar ativamente sua sexualidade e seu desejo (Farwell, "Lesbian Narrative" 157). É portanto a criação desse espaço e a centralidade do desejo lesbiano nestas obras que permitem inseri-las em uma tradição lesbiana na literatura brasileira de autoria feminina. 
BiBLIOGRAFIA

\section{Obras primárias}

Campello, Myriam. "A mulher de ouro". Oprazer é todo meu: contos eróticos femininos. Márcia Denser, org. Rio de Janeiro: Record, 1984. 59-63.

Coutinho, Sonia. "Fátima e Jamila". Uma certa felicidade [1976]. Rio de Janeiro: Rocco, 1994. 131-35.

Denser, Márcia. “Tigresa”. Diana Caçadora. São Paulo: Global, 1986. 119-36.

Telles, Lygia Fagundes. "A escolha". Histórias de amor infeliz. Org. Esdras do Nascimento. Rio de Janeiro: Nórdica, 1985. 129-133.

Van Steen, Edla. "Intimidade". Antes do amanhecer. São Paulo: Editora Moderna, 1977. 65-68.

Obras críticas e secundárias

Anzaldúa, Gloria. "To(o) Queer the Writer-Loca, escritora y chicana". InVersions: Writings by Dykes, Queers and Lesbians. Betsy Warland, ed. Vancouver: Press Gang, 1991. 249-263.

Azevedo, Aluísio. O cortiço [1889]. São Paulo: Atica, 1995.

Bueno, Eva Paulino. "Lygia Fagundes Telles". Latin American Writers oin Gay and Lesbian Themes: A Bio-Critical Sourcebook. David William Foster, ed. Westport, CT/London: Greenwood Press, 1994. 424-427.

Campello, Myriam. Sortilegiu. Rio de Janeiro: Civilização Brasileira; INL, 1981.

Cavalcante, Joyce. O discurso da mulher absurda. São Paulo: Global, 1985.

Cixous, Hélène. "The Laugh of the Medusa". The Signs Reader: Women, Gender and Scholarship [1976]. Keith Cohen e Paula Cohen, trad. Elizabeth Abel e Emily K. Abel, eds. Chicago: University of Chicago Press, 1983. 279-297.

Daniel, Herbert. "Os anjos do sexo". Jacarés e lobisomens: dois ensaios sobre a homossexualidade. Leila Míccolis e Herbert Daniel, eds. Rio de Janeiro: Achiamé; SOCII-Pesquisadores Associados em Ciências Sociais, 1983. 13-68.

De Lauretis, Teresa. The Practice of Love: Lesbian Sexuality and Perverse Desire. Bloomington: Indiana University Press, 1994.

Denser, Márcia, org. Muito prazer. Rio de Janeiro: Record, 1980. O prazer é todo meu: contos eróticos femininos. Rio de Janeiro: Record, 1984.

Faderman, Lillian. "What is Lesbian Literature? Forming a Historical Canon". Professions of Desire: Lesbian and Gay Studies in Literature. George E. Haggerty e Bonnie Zimmerman, eds. Nueva York: MLA, 1995. 49-59.

Farwell, Marilyn R. "The Lesbian Narrative: "The Pursuit of the Inedible by the Unspeakable"'. Professions of Desire: Lesbian and Gay Studies in Literature. George

E. Haggerty e Bonnie Zimmerman, eds. Nueva York: MLA, 1995. 156-68. Heterosexual Plots and Lesbian Narratives. Nueva York: New York University Press, 1996. 
Fitz, Earl E. "Reading Clarice in the Context of Modern Latin American Narrative: a Comparative Assessment". Palestra. "Clarice Lispector: a Symposium". University of Texas at Austin (17 outubro 1997).

Foster, David William. Sexual Textualities: Essays on Queer/ing Latin American Literature. Austin: University of Texas Press, 1997.

(ed.). Latin American Writers on Gay and Lesbian Themes: A Bio-Critical Sourcebook. Lillian Manzor-Coats, Introduction. Westport, CT/Londres: Greenwood Press, 1994.

Gay and Lesbian Themes in Latin American Writing. Austin: University of Texas Press, 1991.

Foucault, Michel. The History of Sexuality I: An Introduction. Robert Hurley, trad. Nueva York: Vintage Books, 1990.

Franconi, Rodolfo Alberto. "Eroticism and Power in the Brazilian Fiction of the '80s". Dissertation Vanderbilt University, 1987.

Haggerty, George E., e Bonnie Zimmerman (eds.). Professions of Desire: Lesbian and Gay Studies in Literature. Nueva York: MLA, 1995.

Humm, Maggie, ed. e introd. Modern Feminisms. Political, Literary, Cultural. Nueva York: Columbia University Press, 1992.

Kristeva, Julia. "Stabat Mater". The Female Body in Western Culture: Contemporary Perspectives. Susan Rubin Suleiman, ed. Cambridge, MA: Harvard University Press, 1986. 99-118.

Lispector, Clarice. "O corpo". A via crucis do corpo. Rio de Janeiro: Artenova, 1974. 2737.

A hora da estrela. Rio de Janeiro: José Olympio, 1977.

Perto do coração selvagem [1944]. Rio de Janeiro: Nova Fronteira, 1980.

“A solução". A legião estrangeira. Rio de Janeiro: Editora do Autor, 1964.

Machado, Gilka. Mulher nua. 1928. Poesias completas. Rio de Janeiro: Léo Christiano Editorial, 1992. 199-262.

Manzor-Coats, Lillian. "Introduction". Latin American Writers on Gay and Lesbian Themes: A Bio-Critical Sourcebook. William David Foster, ed. Westport, CT/ Londres: Greenwood Press, 1994. xv-xxxvi.

Míccolis, Leila. "Prazer, gênero de primeira necessidade". Jacarés e lobisomens: dois ensaios sobre a homossexualidade. Leila Míccolis e Herbert Daniel, eds. Rio de Janeiro: Achiamé; SOCII-Pesquisadores Associados em Ciências Sociais, 1983. 69119.

Molloy, Sylvia. "Introduction. Female Textual Identities: The Strategies of SelfFiguration". Women's Writing in Latin America: An Anthology. Sara Castro-Klarén, Sylvia Molloy e Beatriz Sarlo, eds. Boulder, CO: Westview Press, 1991. 107-124.

Mott, Luís. O lesbianismo no Brasil. Porto Alegre: Mercardo Aberto, 1987.

Piñon, Nélida. A casa da paixão [1972]. Rio de Janeiro: Francisco Alves, 1988.

Pratt, Annis, et al. Archetypal Patterns in Women's Fiction. Bloomington: Indiana University Press, 1981.

Queiroz, Raquel de. As três Marias [1939]. Obra reunida II: As três Marias. Dôra, Doralina. Rio de Janeiro: José Olympio, 1989. 
Quinlan, Susan C. "O animal dos motéis: novela em episódios. I Write to Describe All Sides of Myself". The Female Voice in Contemporary Brazilian Narrative. Nueva York: Peter Lang, 1991. 103-137.

Rich, Adrienne. "Compulsory Heterosexuality and Lesbian Existence". The Signs Reader: Women, Gender and Scholarship [1980]. Elizabeth Abel e Emily K. Abel, eds. Chicago: University of Chicago Press, 1983. 139-168.

Smith, Barbara. "Toward a Black Feminist Criticism". Women's Studies International Quaterly 2/2 (1979): 183-194.

Stimpson, Catherine. "Zero Degree Deviance: The Lesbian Novel in English". Criticial Inquiry 8/2 (1981): 363-379.

Telles, Lygia Fagundes. Ciranda de pedra [1954]. Rio de Janeiro: Nova Fronteira, 1984. As meninas [1973]. Rio de Janeiro: José Olympio, 1974.

"Tigrela". Seminário dos ratos. Rio de Janeiro: Nova Fronteira, 1977. 131-137.

Villares, Laura. Vertigem. São Paulo: Editora Antonio Tisi, 1926.

Zimmerman, Bonnie. The Safe Sea of Women: Lesbian Fiction, 1969-1989. Boston: Beacon, 1990. 
